\title{
PREVISÃO DE CARGA ELÉTRICA NO CURTO PRAZO COM REDES NEURAIS
}

\author{
Angel Santiago Fernandez Bou ${ }^{1}$ \\ Vitor Hugo Ferreira ${ }^{2}$
}

\begin{abstract}
RESUMO: A previsão da carga elétrica que vai ser consumida em um determinado horizonte temporal tem-se tornado um dos alvos das pesquisas das empresas concessionárias de energia elétrica. Ao longo das últimas décadas, diversos métodos de cálculo estatístico têm sido usados para realizar estas previsões; no entanto, com a evolução da computação, novas técnicas baseadas na inteligência artificial conseguiram desenvolver-se com bons resultados. Uma das técnicas que oferecem melhores resultados é a de Redes Neurais Artificiais, já que apresenta alta capacidade de lidar com comportamentos não lineares, como os que acontecem na demanda de potência elétrica. Neste artigo estudou-se uma série de dados de carga elétrica horária e de temperatura horária durante dois meses para realizar a previsão da potência elétrica horária demandada durante os sete dias posteriores à série, utilizando a técnica de Redes Neurais Artificiais. A hipótese de partida usada foi que a carga elétrica depende da temperatura. Para alimentar a Rede Neural utilizaram-se como entradas a evolução do consumo, a temperatura horária e um coeficiente dependente da temperatura. Este coeficiente tentou destacar o efeito da não linearidade da série. $\mathrm{O}$ menor erro percentualmédio obtido com o modelo após aplicar diversas parametrizações foi de $3,41 \%$. Este resultado pode ser considerado bom, ficando provado que a técnica de Redes Neurais Artificiais fornece boas previsões para o cálculo da potência elétrica demandada no curto prazo.
\end{abstract}

PALAVRAS-CHAVE: Previsão de Carga para Curto Prazo; Redes Neurais.

\section{SHORT-TERM LOAD FORECASTING USING NEURAL NETWORKS}

ABSTRACT:Short-term load forecasting has become one of the main research targets of the electric sector. During the last decades, several calculation methods have been used to make these forecasts. However, with the computation development, techniques based on artificial intelligence reached a better level of development with good results. One of the techniques which return the best results is Artificial Neural Networks, because it can work with non-linear behaviors like the ones at electric load demand. In this paper, time-series of hourly load and hourly temperature during two months were studied to make the hourly load forecast for the next seven days, using the Artificial Neural Networks technique. The beginning hypothesis was the load depends on the temperature. The inputs used to feed the Neural Network were the electricity consumption evolution, the hourly temperature and a temperature dependent coefficient. This coefficient intended to emphasize the non-linear effect of the series. The minimum mean absolute percentage error got with this model after using several parameter settings was $3,41 \%$. This result can be considered good, proving the potential of Artificial Neural Networks technique when applied for short term load forecasting.

KEYWORDS: short-term load forecast, neural networks

\footnotetext{
${ }^{1}$ Universidade Federal Fluminense, Rua Passo da Pátria, 156, Niterói - RJ. CEP:24210-240; asfernandezbou@id.uff.br

${ }^{2}$ Universidade Federal Fluminense, Rua Passo da Pátria, 156, Niterói - RJ. CEP:24210-240; vitor@vm.uff.br
} 


\section{INTRODUÇÃO}

Em muitos países, a eletricidade é uma mercadoria que é comprada por empresas concessionárias e revendida para os usuários finais, com o objetivo de obter lucro. Um dos maiores desafios deste tipo de empresas é ter boas previsões de consumo num determinado horizonte temporal, desde minutos ou horas até décadas, para poder saber antecipadamente quanta potencia elétrica contratar e, desta forma, conseguir um lucro maior. Especialmente as previsões no curto prazo têm-se tornado alvo de pesquisa com o intuito de melhorar a competitividade deste tipo de empresa (Steinherz Hippert et al., 2001).

Para realizar essas previsões, era habitual o uso de métodos de análise das séries de dados baseados na estatística, como o método ARIMA (AutoregressiveIntegratedMovingAverag e)de Box e Jenkins. Este modelo pretende determinar o padrão dos dados para ser capaz de realizar extrapolações que permitam fazer predições (Collantes Duarte et al., 2004).

No entanto, nos últimos tempos, graças à evolução da tecnologia da computação, novas técnicas apareceram e se desenvolveram, sendo uma das mais usadas para previsão de potencia elétrica a das Redes Neurais Artificiais, RNA, por apresentar bons resultados (Chang-il et al., 2002).

\section{As Redes Neurais Artificiais}

As Redes Neurais Artificiais têm seu funcionamento inspirado nos neurônios do cérebro humano, descritos como elementos funcionais do sistema nervoso por primeira vez na História no final do século XIX pelo cientista espanhol Santiago Ramón y Cajal(LópezMuñoz et al., 2006). Esta descoberta levou a Ramón y Cajal a ganhar o prêmio Nobel de Medicina em 1906, junto com o cientista italiano Camilo Golgi, também um dos precursores dos estúdios do sistema nervoso (Muscatello, 2007).
Por sua parte, as Redes Neurais Artificiais tiveram seu início com um artigo de Mcculloch e Pitts, em 1943, onde se defende que a dinâmica dos neurônios é de "tudo ou nada" e pode ser, portanto, considerada um comportamento lógico (McCulloch and Pitts, 1943).

As Redes Neurais Artificiais são sistemas de tratamento de dados de maneira a entender como esses dados evoluem; assim, elas aprendem entendendo as relações que podem existir entre os dados com que trabalham, tratando-os como estatística multivariada não linear e não paramétrica (CervantesOsornio et al., 2011). Deste modo, baseando-se nos dados que as alimentam, as RNA são capazes de fazer previsões de como esses dados evoluirão.

Para aplicar um modelo de RNA deve definir-se a saída desejada, que é o resultado, e as entradas que influenciam nessa saída. Ao treinar a rede, esta fornecerá os pesos das entradas na determinação do resultado (Figura 1).

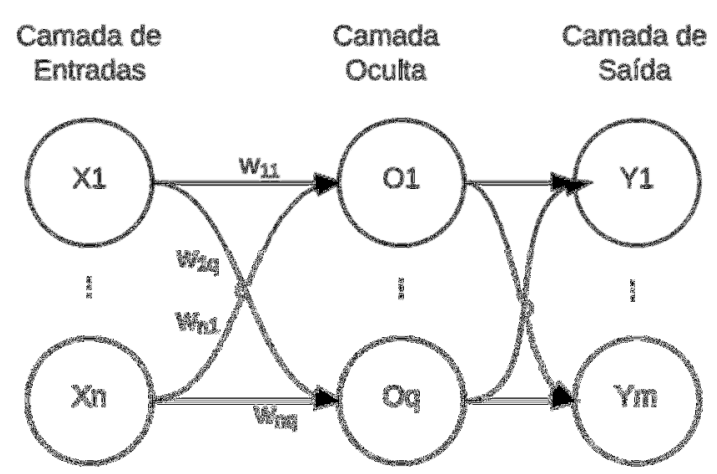

Figura 1 - Estrutura simplificada de uma rede neural

Para otimizar o treinamento, a rede utiliza uma função de desempenho que deve ser minimizada, como o MSE (erro mínimo quadrático).

A RNA precisa de dados suficientes para entender o seu comportamento; separa uma parte dos dados para realizar o treinamento, que é uma parametrização dos pesos de cada entrada, outra parte para validá-lo e uma ultima parte para testá-lo.

A atualização dos pesos se dá de acordo ao sentido decrescente da função 
de desempenho, que é o negativo do gradiente, como pode observar-se na Equação 1: Algoritmo de retropropagação do erro (Cervantes-Osornio et al., 2011).

$$
\omega_{\mathrm{k}+1}=\omega_{\mathrm{k}}-\alpha_{\mathrm{k}} \cdot \eta_{\mathrm{k}}
$$

Onde:

$\omega$ é o peso sináptico;

$\alpha$ é o gradiente da função de desempenho;

$\eta$ é a taxa de aprendizagem;

$\mathrm{k}$ é um instante de tempo.

\section{Aplicações das Redes Neurais}

As Redes Neurais são uma tecnologia relativamente nova que ainda está sendo aperfeiçoada. No entanto, na atualidade, as Redes Neurais Artificiais funcionam bem na previsão de sistemas não lineares.

Entre muitos exemplos, até hoje esta técnica foi usada em situações como a previsão e modelagem de falhas em manutenção industrial (Torres Jr et al., 2010);para prever a incidência da dengue (Strini, 2006); para modelar processos de tratamento de efluentes orgânicos e prever a concentração de nitrogênio dentro do reator biológico(Salviano, 2002); para modelagem de vazões de rios baseadas na previsão meteorológica (Biondi Neto et al., 2010, Sousa and Sousa, 2010, Montenegro, 2009), entre outras aplicações.

\section{Objetivo do estudo}

Neste artigo se propõe o estudo da técnica de redes neurais para realizar a previsão de carga (potência) horária de uma determinada semana, baseada nos dados de temperatura e de carga elétrica de algumas semanas anteriores. Partiu-se da hipótese de que a carga elétrica consumida depende da evolução da carga consumida até o momento e da temperatura local.

Os dados correspondem a uma região fria dos Estados Unidos, entre $31 / 08 / 2001$ e 30/10/2001, e a previsãorealizada foi para as 168 horas entre o dia 31/10/2001 e 06/11/2001.

\section{MATERIAL E MÉTODOS}

A rede neural é um instrumento puramente matemático, ou seja, não tem capacidade de interpretar outra coisa que não seja dados e parâmetros. Por isso, a qualidade da previsão depende sempre da qualidade dos dados e da capacidade do usuário de fazer os melhores ajustes nos parâmetros.

No caso estudado, não existe uma serie muito longa de dados disponíveis. Assim, a rede funcionará bem se todos os dados indicam o mesmo (existe pouca variabilidade); se os parâmetros são ajustados corretamente $\mathrm{o}$ resultado também pode ser adequado. No entanto, se os dados e os parâmetros se apresentam de maneira errada ou desajustada, a previsão poderá não representar corretamente a realidade.

\section{Análise dos dados}

O primeiro passo no processo de elaboração da previsão da carga horária foi a análise dos dados. Para uma mais fácil interpretação se usou o programa Excel para representar graficamente a série. Criou-se inicialmente um gráfico (Figura 2) com a carga diária consumida e a temperatura média diária. Neste gráfico se observou um padrão de consumo claro, que constata que aos fins de semana (sábados e domingos) o consumo é menor que os outros dias da semana. Observa-se um outlier o dia 03/09/2001, que apresenta um consumo similar ao do fim de semana; isso se justifica com o calendário dos EUA, no qual se celebra na primeira segunda-feira de cada mês de setembro o Labors's Day (Dia do Trabalho), que é feriado nacional.

Outro detalhe importante que se observa no gráfico é que, quando a temperatura é superior à média da série, o consumo de energia acontece de maneira não linear, com um padrão claramente mais influenciado pela variabilidade da temperatura. Isto sugere a existência de um intervalo de "temperatura de conforto", que é parcialmente subjetivo, e dependente de cada usuário e cada 
comunidade. Por isso, é importante destacar que este acontecimento se dá nesta serie de dados, mas pode não acontecer da mesma maneira em outras séries de dados de outros lugares ou outras épocas do ano.

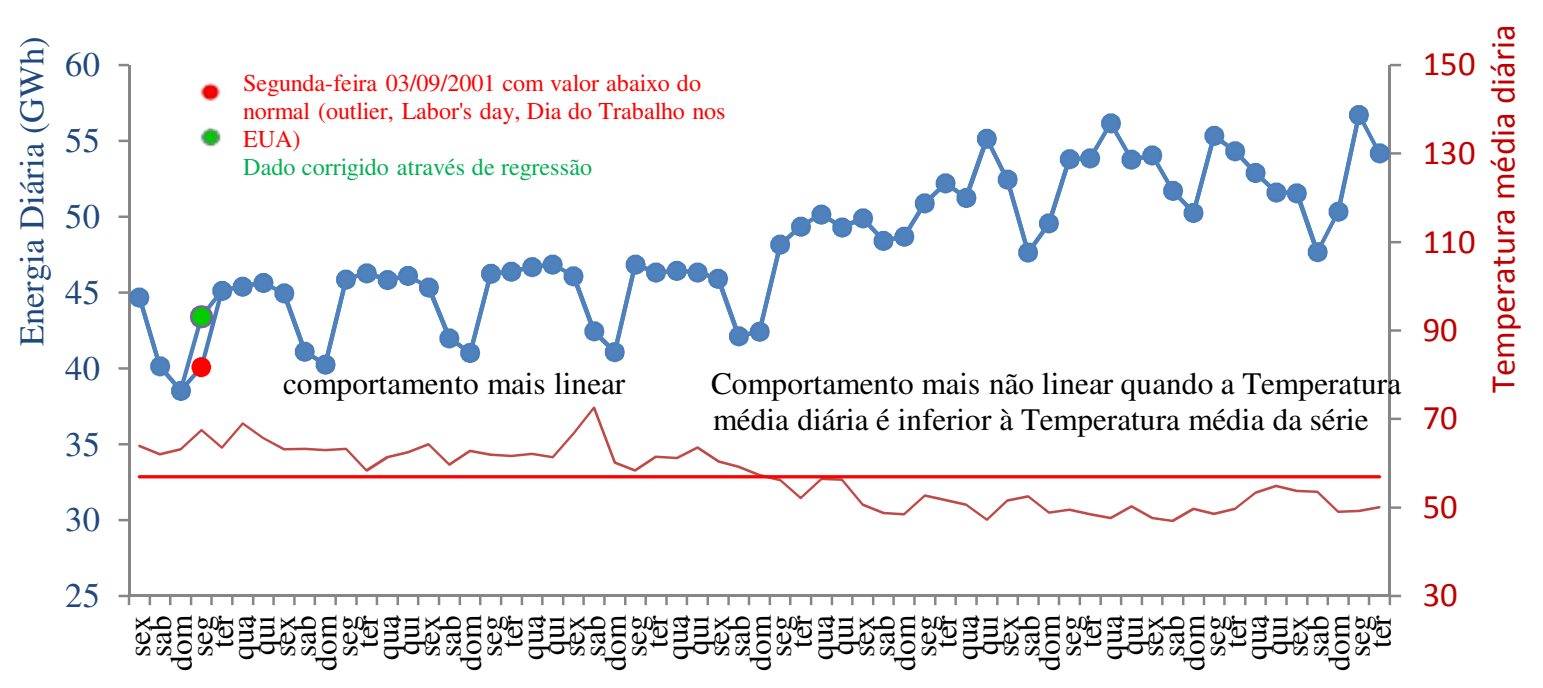

Figura 2. Dados de energia diária consumida (eixo principal) e de temperatura média diária (eixo secundário). Observa-se a presença de um outlier (segunda-feira 03/09/2001).

Por último, outra observação relevante que aparece no gráfico é que, quanto menor a temperatura, maior o consumo. De novo, isto não pode ser extrapolado para qualquer série de dados; se entende que, quando faz frio, menor temperatura aumenta o consumo de energia para calefação, mas, quando faz calor, uma maior temperatura aumentará o consumo de energia para atender a demanda de ar condicionado. Existe um intervalo de temperaturas que pode ser considerado "confortável" para o ser humano, onde pequenas variações de temperatura não influenciam significativamente no consumo de energia.
Criou-se um segundo gráfico com todos os dados horários de carga e de temperatura (Figura 3); este gráfico apresenta a evolução hora a hora da carga e da temperatura. Pode observar-se a tendência da temperatura e da energia a oscilar entre o dia e a noite. No caso da temperatura, a oscilação horária em um dia é, na maioria das datas, maior que a oscilação da temperatura média entre o início e o fim da série. No caso da carga horária, pode observar-se que, mesmo sendo maior o consumo total quando a temperatura média é inferior (Figura 2), o consumo horário depende do período do dia, sendo à noite o menor consumo. 


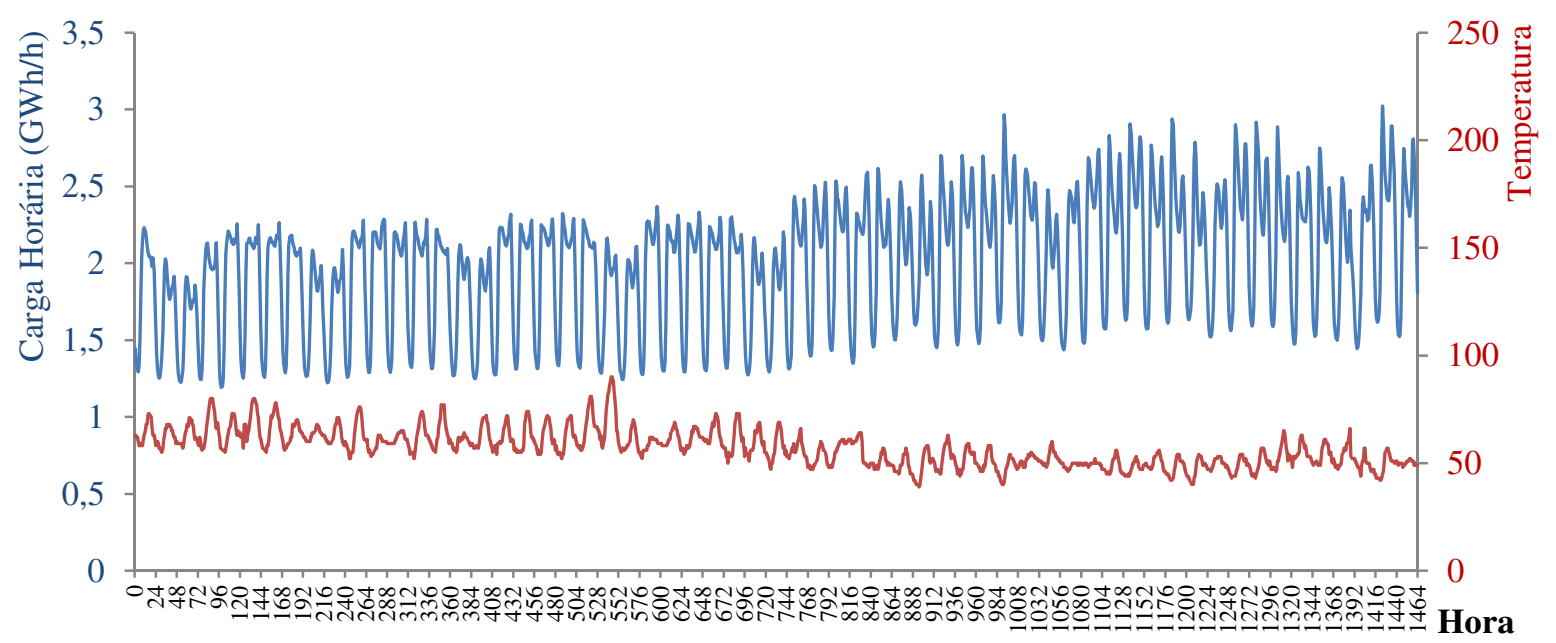

Figura 3. Apresentação dos dados horários de carga e de temperatura de toda a série

Para ver esse efeito mais claramente, criou-se um gráfico que apresenta a evolução da carga e da temperatura ao longo de 24 horas (Figura 4). Assim se observa que no horário noturno a temperatura é menor, mas o consumo diminui, provavelmente, pela falta de atividade humana. No início da manhã o consumo aumenta expressivamente entre as $5 \mathrm{~h}$ e as $8 \mathrm{~h}$, quando atinge um pico, e diminui levemente durante o dia, que a temperatura é maior, até o início da noite, que há um novo pico antes de o consumo baixar até o mínimo diário durante a madrugada.

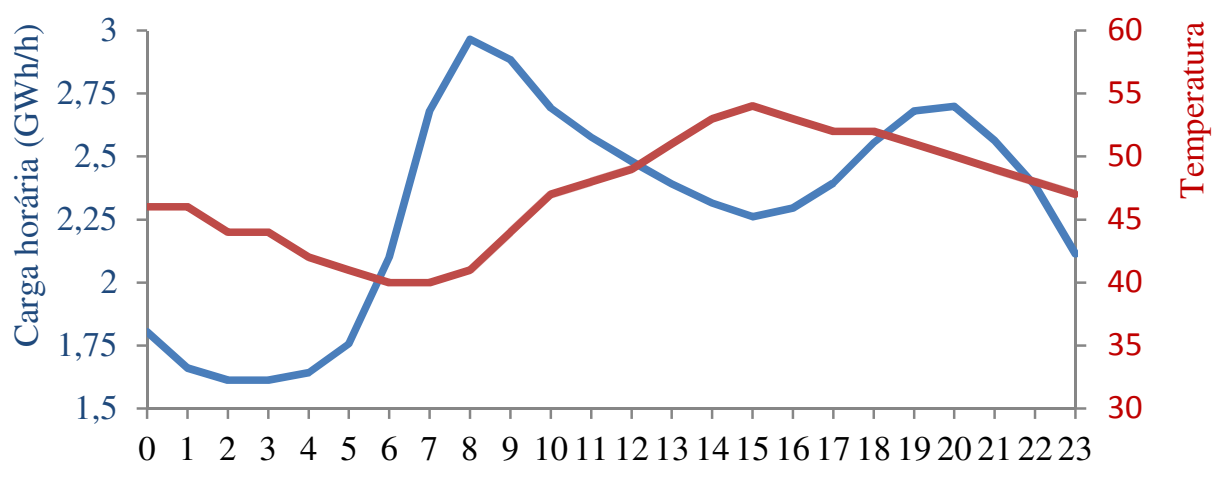

Figura 4. Apresentação dos dados horários de carga e de temperatura durante as 24 horas de um dia qualquer (11/10/2001).

\section{Interpretação dos dados}

Para um funcionamento melhor da rede neural, devem decidir-se as entradas que serão usadas e os lags (atrasos) das entradas e da saída desejada (para ela funcionar como uma entrada mais). $\mathrm{O}$ fator limitante são os dados e o conhecimento que o usuário tem deles.

Como o objetivo deste estudo é prever a carga horária de uma semana futura, logo após a série de dados fornecida, serão supostos os fatores a seguir para poder definir de que depende o consumo horário:

- O consumo de uma determinada hora depende do consumo de uma semana atrás ou 168 horas (este fato faz com que o outlier possa influenciar negativamente). Depende também do consumo das últimas horas e da sequência dia/noite. Isso significa que o consumo segue um determinado hábito.

- O consumo depende da temperatura nas últimas horas ou dias. 
Isso significa que o consumo está influenciado pela variabilidade meteorológica e climática.

- A variação do consumo é diferente se a temperatura está acima ou abaixo da média da série. Isso significa que o consumo depende da sensação de conforto pretendida pelo consumidor.

\section{neural \\ Software para criação da rede}

Para realizar a previsão foi usado o software MATLAB 7.10.0 (2010a). O MATLAB possui diversas bibliotecas orientadas ao desenvolvimento de Redes Neurais Artificiais, que facilitam sua utilização, fazendo deste software uma ferramenta recomendável para trabalhar com esta técnica.

\section{Programas necessários para a previsão}

Foram criados quatro programas, sendo dois deles principais para poder achar uma previsão melhor: o primeiro foi para avaliação da estrutura da rede, parâmetros, modelos, etc., e o segundo foi para realizar a previsão, baseado nos melhores resultados obtidos no primeiro.

Todos os resultados das diferentes provas do primeiro programa foram anotados em uma planilha de Excel com o objetivo de poder calcular o menor MAPE (meanabsolutepercentageerror) como critério de seleção da melhor combinação de parâmetros e o modelo para realizar a previsão.

Ainda se criou um programa acessório para corrigir o outlier mediante regressão. Com o outlier corrigido, esperava-se que a tendência da previsão fosse a melhorar.

Criou-se um quarto programa a modo de teste, com uma estrutura diferente de entradas. Este programa não considerou o efeito da sensação de conforto desejada pelo consumidor, e as previsões mostraram-se piores, sendo, portanto, descartado em favor do primeiro dos programas principais.

\section{Padronização dos dados}

Antes de começar o desenvolvimento do programa, avaliou-se a apresentação dos dados. Para simplificar a programação e poder usar as mesmas funções no processamento dos diferentes arquivos de dados do Excel, estes foram padronizados. Todos os arquivos usados para as entradas e saída desejada foram construídos com duas colunas de texto à esquerda, correspondentes ao dia da semana e à data, e uma linha superior indicando a hora do dia. É relevante que o formato do dia da semana (segunda-feira, terça-feira, etc.) seja sempre o mesmo.

Os dados numéricos para o treinamento do primeiro programa são, portanto, apresentados no Excel como uma matriz de 61 linhas (dias da série) por 24 horas (em um dia), dando 1464 valores horários. Para o processamento pelos programas foi preciso transformar essas matrizes em vetores coluna. Esse processo pode ser feito com o Excel, mediante uma macro em Visual Basic ou com uma função no MATLAB. Nos dois casos cada linha de 24 horas será transposta e colocada em uma única coluna, acumulando os dados em uma sequencia horária.

\section{modelos}

Programa para validação de

O primeiro programa teve como missão testar diversas parametrizações e modelos para decidir qual seria usada na previsão.

Inicialmente, declararam-se todas as variáveis necessárias para o treinamento, validação e teste. Como os dados estavam em planilhas em formato Excel, o processamento dos mesmos realizou-se com a ajuda da função do MATLAB xlsread, que extraiu os dados de cada planilha de modo que outra função pudesse concatená-los em um só vetor.

Os dados dividiram-se em dois grupos; o primeiro, com todos os dados de carga e temperatura menos a última semana (168 horas), e o segundo com os dados da última semana. 
Com os dados do primeiro grupo realizou-se o treinamento e a validação, testando diferentes parametrizações; com cada uma dessas configurações se fez a previsão da última semana de dados disponíveis, tendo o programa como resultado um vetor com 168 dados de carga horária. Este vetor, para cada uma das combinações testadas, foi alimentando uma planilha de Excel, onde também estavam registrados os dados reais dessa última semana.

Comparando os dados previstos com os dados reais se obteve o MAPE de cada combinação aplicando a Equação 2: MAPE (meanabsolutepercentageerror).

$$
\text { MAPE }=\frac{1}{N} \sum_{i=1}^{\mathrm{N}} \frac{\left|\operatorname{Carga}_{\text {real }}(\mathrm{i})-\mathrm{Carga}_{\text {previsão }}(\mathrm{i})\right|}{\mathrm{Carga}_{\text {real }}(\mathrm{i})} \cdot 100
$$

Sendo $N$ o número de horas (168).

A seleção dos testes a serem feitos foi escolhida pelo usuário, que se baseou na interpretação dos dados e em experiências prévias, já que não foi possível testar todas as possibilidades por limitações de tempo e porque algumas configurações são claramente piores que outras.

Os parâmetros que podiam ser variados foram:

- Semente: ponto de inicialização do programa que deve ser o mesmo para poder não depender da variabilidade devido a sua aleatoriedade.

- Lag(atraso) da saída desejada.

Este parâmetro representa como dados passados de carga horária representam os atuais. $\mathrm{O}$ consumo depende da época do ano, do dia da semana e da hora do dia, mas não há dados suficientes para que o lag seja interpretado anualmente. Assim, se decidiu testar lags da saída desejada de 168 horas (uma semana) ou menores.

- Entradas: são os inputs do sistema que devem influenciar na saída. As entradas são os dados mais relevantes para conseguir uma boa previsão. Para este estudo, os únicos dados disponíveis eram temperatura e carga, e as entradas se adaptaram a essa restrição.

- Entrada 1: Temperatura.

Dados diretos de temperatura horária. Inicialmente criou-se um programa que tinha como entradas, além dos lags da carga horária, unicamente a temperatura; no entanto, com o intuito de melhorar a previsão, decidiu-se introduzir um novo grupo de entradas, baseadas também na temperatura (Entrada 2).

- Entrada 2: coeficiente de temperatura. Baseado na análise inicial dos dados (Figura 2), quando a temperatura é inferior à temperatura média da série, a evolução do consumo da carga é diferente; isso foi apresentado na Entrada 2 de maneira que, quando a temperatura horária estivesse acima da média, o coeficiente seria 0 , e quando estivesse abaixo da média, o coeficiente seria um valor exponencial relacionado à temperatura horária. Desenhou-se a Equação 3: Coeficiente de temperaturapara atender este quesito de não linearidade.

$$
\text { Se } T^{\mathrm{a}}(\mathrm{k}) \geq \overline{\mathrm{T}}^{\mathrm{a}} \rightarrow \text { Coef. } \mathrm{T}^{\mathrm{a}}(\mathrm{k})=0
$$

Se $\mathrm{T}^{\mathrm{a}}(\mathrm{k})<\overline{\mathrm{T}}^{\mathrm{a}} \rightarrow$ Coef. $\mathrm{T}^{\mathrm{a}}(\mathrm{k})=\alpha^{\left|\mathrm{T}^{\mathrm{a}}(\mathrm{k})-\overline{\mathrm{T}}^{\mathrm{a}}\right|}$

Onde:

$\mathrm{T}^{\mathrm{a}}(\mathrm{k})$ é a temperatura da hora $\mathrm{k}$;

$\bar{T}^{a}$ é a temperatura média da série ;

Coef. $\mathrm{T}^{\mathrm{a}}(\mathrm{k})$ é o valor do coeficiente que alimenta a matriz da Entrada 2 e que visa representar a não linearidade do sistema;

$\alpha$ é a base do coeficiente. Testaramse os valores $e$ (constante de Euler), 2, 1, $0,9,0,8$ e 0,5 .

- Lags (atrasos) das entradas. Como a temperatura não tem um comportamento baseado no dia da semana testaram-se lags de até 96 horas.

- Número de neurônios. Testados desde 1 neurônio até 12 (1:12).

- Percentual de dados para validação. São os dados dedicados ao treinamento que são reservados para 
validar se o mesmo está correto. Testado $15 \%$ e $20 \%$.

- Modelo de treinamento. Os modelos de treinamentos testados foram três:

- Gradiente Conjugado.

- Levenberg-Marquardt.

- Treinamento Bayesiano.

- Número de épocas.

\section{RESULTADOS E DISCUSÃO}

\section{Resultados do primeiro programa \\ Foram modificados todos os} parâmetros sem fixar inicialmente a semente para, uma vez definido o melhor treinamento, determinar uma semente que se equiparasse ao melhor resultado obtido com sementes aleatórias. Conforme iam sendo testadas as diferentes parametrizações, os resultados eram anotados detalhadamente em uma planilha de Excel, onde foram comparados com os valores reais. A previsão do programa se apresenta na Figura 5.

Inicialmente os três tipos de treinamento tiveram resultados similares; no entanto, à medida que o número de testes ia aumentando, podia observar-se uma supremacia leve do treinamento de Gradiente Conjugado.

Uma vez escolhido o modelo, introduziu-se uma semente fixa, para evitar a aleatoriedade de uma previsão para outra e deixar o sistema determinista.

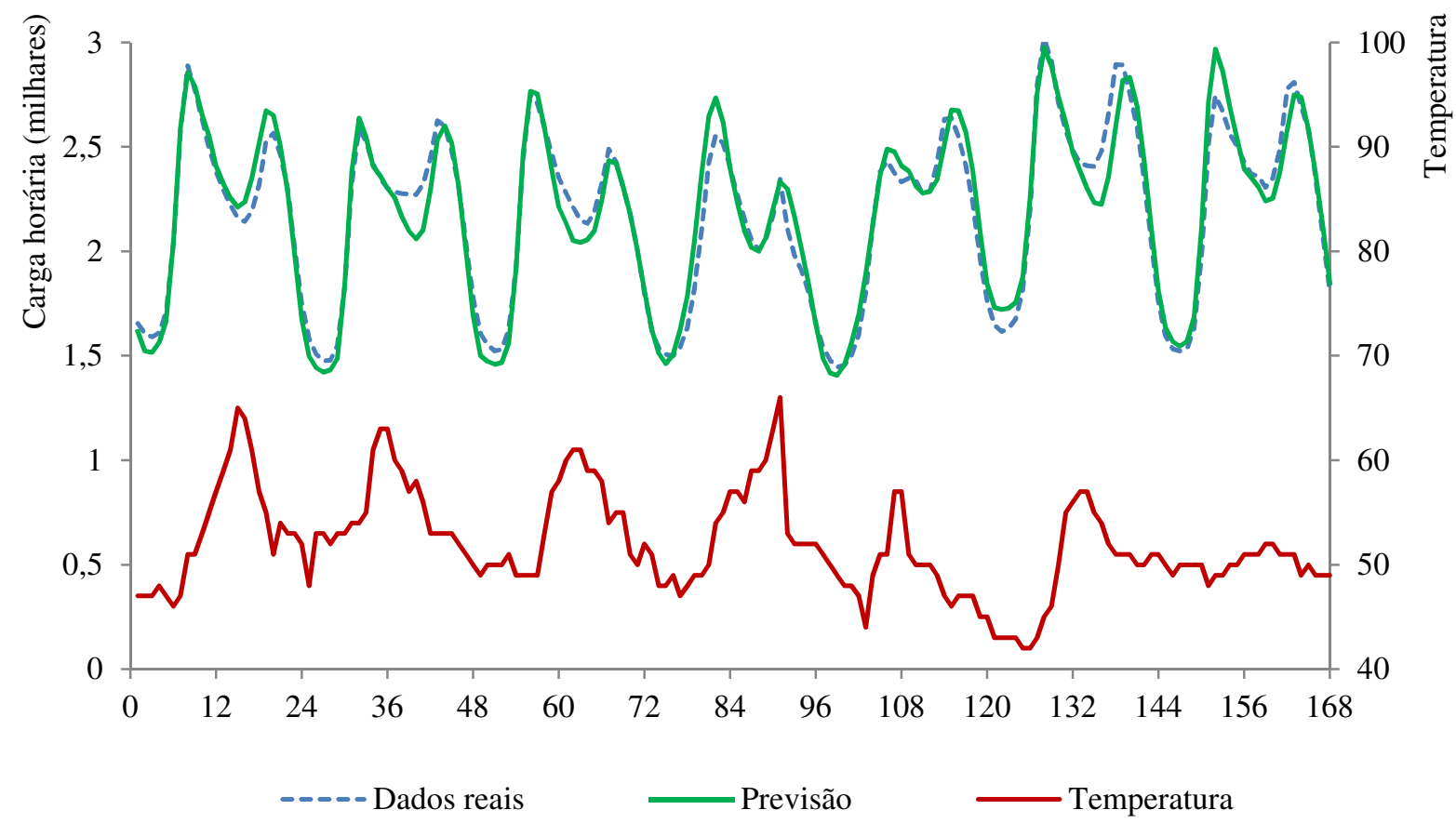

Figura 5. Previsão realizada pelo primeiro programa para os últimos 168 dados horários da série

Melhor semente: 100000

Se $T^{\mathrm{a}}(\mathrm{k}) \geq \overline{\mathrm{T}}^{\mathrm{a}} \rightarrow$ Coef. $\mathrm{T}^{\mathrm{a}}(\mathrm{k})=0$

Entrada 1: Temperatura

Entrada 2: Coeficiente de temperatura com $\alpha=0,9$, ficando aEquqção 3 definida como a Equação 4: Coeficiente de temperatura definido.

Se $\mathrm{T}^{\mathrm{a}}(\mathrm{k})<\overline{\mathrm{T}}^{\mathrm{a}} \rightarrow$ Coef. $\mathrm{T}^{\mathrm{a}}(\mathrm{k})=0,9^{\left|\mathrm{T}^{\mathrm{a}}(\mathrm{k})-\overline{\mathrm{T}}^{\mathrm{a}}\right|}$

Onde:

$\mathrm{T}^{\mathrm{a}}(\mathrm{k})$ é a temperatura da hora $\mathrm{k}$; 
$\overline{\mathrm{T}}^{\mathrm{a}}$ é a temperatura média da série;

Coef. $\mathrm{T}^{\mathrm{a}}(\mathrm{k})$ é o valor do coeficiente que alimenta a matriz da Entrada 2 e que visa representar a não linearidade do sistema.

Melhor lag da saída (Carga horária): 1:168. Isso significa que a carga horária em um momento $\mathrm{k}$ tem alguma dependência da carga horária durante a última semana. Assim pode ser explicado o consumo menor aos fins de semana e entre o dia e a noite.

Melhor lag da Entrada 1: 0:72. Significa que a carga horária depende da temperatura atual e de das temperaturas horárias dos últimos três dias.

Melhor lag da Entrada 2: 0:72.

Melhor número de neurônios: 1 .

Percentual de dados para validação:

20\% (sem diferença com 15\%)

Épocas: 10.000.

Melhor modelo: Gradiente Conjugado.

Função de desempenho: erro dos mínimos quadrados

MAPE: 3,4156\% (diferença entre valor real e o previsto).

\section{Programa de correção do outlier}

Com os parâmetros definidos pelo primeiro programa, criou-se um segundo baseado nele para correção do outlier correspondente ao dia 03/09/2001. Assim, se refez a base de dados de carga horária.

Com os dados corrigidos testou-se de novo o primeiro programa, que melhorou levemente a precisão da previsão $(3,4196 \%$ com o outlier para $3,4156 \%$ ). A melhora foi tão pequena que poderia considerar-se desprezível.

\section{horária \\ Programa de previsão de carga \\ Uma vez selecionados os} parâmetros com melhores resultados de previsão, o primeiro programa adaptou-se aos dados de previsão. Assim, o treinamento foi feito com todos os dados de cargas horárias, com o outlier corrigido, e todos os dados de temperatura, inclusive para o cálculo do coeficiente de temperatura. Para a previsão foi usada a temperatura prevista (série de 168 horas consecutivas à última data e hora da série de dados do primeiro programa).

A previsão do segundo programa se apresenta na Figura 6.

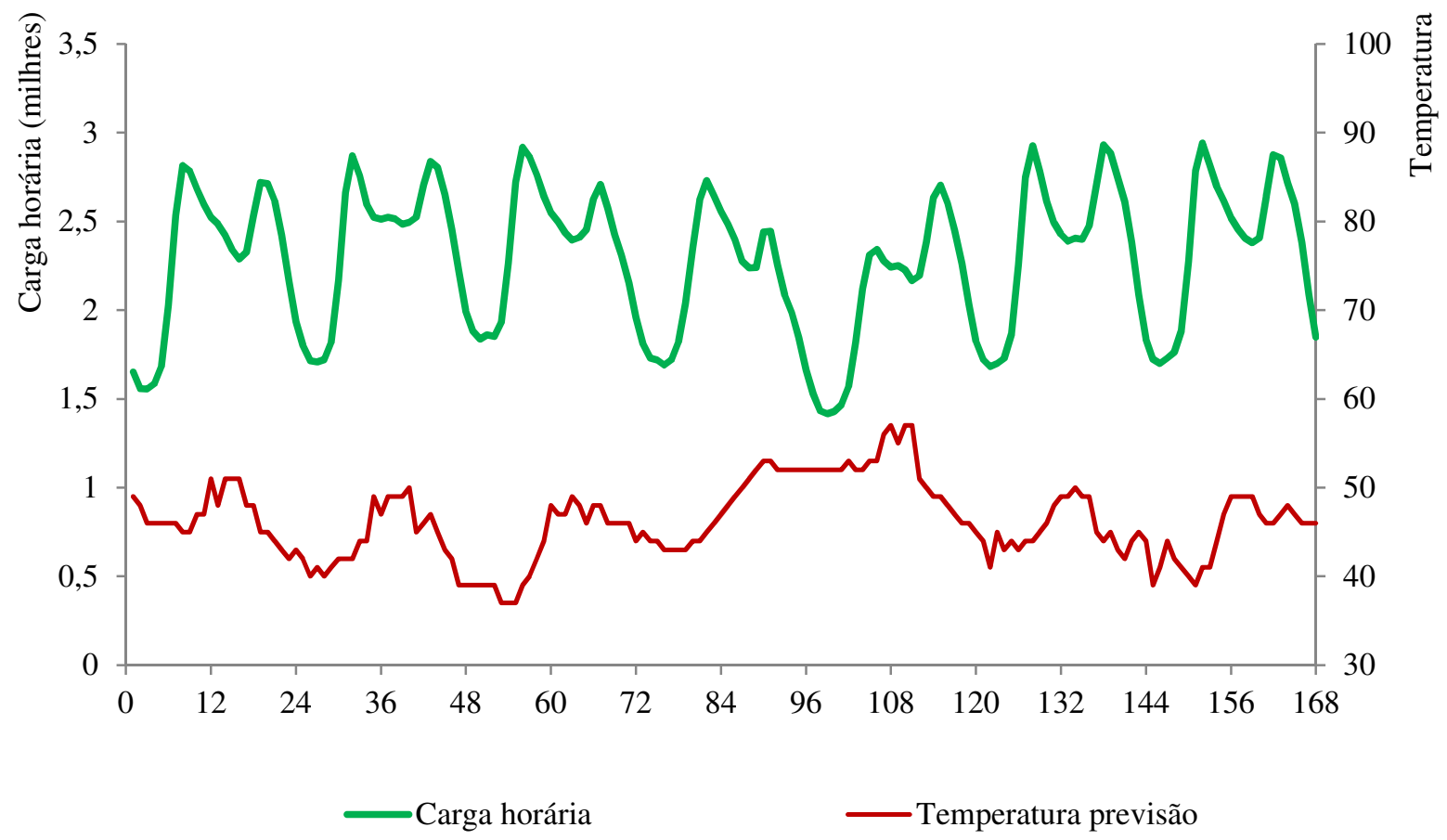

Figura 6. Previsão do segundo programa 


\section{CONCLUSÕES}

O primeiro programa conseguiu uma previsão melhor para o treinamento de Gradiente Conjugado, com MAPE de 3,415\%; o treinamento de LevenbergMarquardt teve MAPE de 3,425\% e o Bayesiano de 3,455\%.

Isso comprova que a previsão de carga horária através da técnica de Redes Neurais Artificiais pode ser considerada de boa qualidade.

Para melhorar as previsões poderiam estudar-se simultaneamente outras variáveis de entrada que tenham influência na demanda de potência elétrica, como a umidade relativa, que influencia na sensação de conforto, a velocidade do vento, a radiação solar, os dias com e sem nuvens, etc.

Outra possível melhora na precisão das previsões é a definição dos intervalos de "temperatura de conforto". Por serem de natureza parcialmente subjetiva, um estudo a nível local pode melhorar a precisão nos lugares diferenciados.

Com a evolução constante dos computadores, Redes Neurais Artificiais mais complexas, que precisem de uma capacidade de processamento computacional mais elevada, serão cada vez mais acessíveis, o que facilitará a popularização do seu uso.

Por outro lado, a modelagem com Redes Neurais Artificiais pode ser usada conjuntamente com outras técnicas para obter resultados mais precisos ou mais abrangentes.

\section{AGRADECIMENTOS}

À CAPES pelo apoio financeiro.

\section{REFERÊNCIAS}

BIONDI NETO, L., COELHO, P. H. G., CHIGANER, L., MEZA, L. A. \& MONTEIRO, L. P. 2010. Previsão da
Vazão afluente mensal do rio São Francisco usando-se redes de Elman. Engevista, 7, 63-72.

CERVANTES-OSORNIO, R., ARTEAGA-RAMÍREZ, R., VÁZQUEZPEÑA, M. A. \& QUEVEDONOLASCO, A. 2011. Redes neuronales artificiales en la estimación de la evapotranspiración de referencia. Revista mexicana de ciencias agrícolas, 2, 433447.

CHANG-Il, K., In-KEUN, Y. \& SONG, Y. H. 2002. Kohonen neural network and wavelet transform based approach to short-term load forecasting. Electric Power Systems Research, 63, 169-176.

COLLANTES DUARTE, J., COLMENARES La CRUZ, G., ORLANDONI MERLI, G. \& Rivas Echeverría, F. 2004. A comparison of time series forecasting between artificial neural networks and Box and Jenkins methods. Revista Técnica de la Facultad de Ingeniería Universidad del Zulia, 27, 146-160.

LÓPEZ-MUÑOZ ， F., BOYA, J. \& ALAMO, C. 2006. Neuron theory, the cornerstone of neuroscience, on the centenary of the Nobel Prize award to Santiago Ramón y Cajal. Brain Research Bulletin, 70, 391 - 405.

MCCULLOCH, W. S. \& PITTS, W. 1943. A logical calculus of the ideas immanent in nervous activity. Bulletin of Mathematical Biology, 52, 99-115.

MONTENEGRO, R. 2009. Previsão de séries de vazão do rio São Francisco utilizando dados históricos da temperatura da superfície do mar.

MUSCATELLO, U. 2007. Golgi's contribution to medicine. Brain Research Reviews, 55, 3 - 7. 
SALVIANO, F. O. C. 2002. Modelagem $e$ simulação de um tratamento de efluentes organicos atraves de redes neurais. MSc, Universidade Estadual de Campinas.

SOUSA, W. D. S. \& SOUSA, F. D. A. S. D. 2010. Rede neural artificial aplicada à previsão de vazão da Bacia Hidrográfica do Rio Piancó. Revista Brasileira de Engenharia Agrícola e Ambiental, 14, 173-180.

STEINHERZ HIPPERT, H., PEDREIRA, C. E. \& Castro Souza, R. 2001. Neural Networks for Short-Term Load Forecasting: A Review and Evaluation IEEE TRANSACTIONS ON POWER SYSTEMS, 16, 12.

STRINI, E. J. 2006. Previsão da incidência de dengue por meio de redes neurais artificiais, FFCLRP/USP.

TORRES Jr, R. G., MACHADO, M. A. S. \& Souza, R. C. 2010. Previsão de séries temporais de falhas em Manutenção industrial usando redes neurais. Engevista, 7. 